\title{
NeST SUCCESS OF YELLOW WARBLERS IN Willow Habitats: THE Role OF SURFACE WATER AND SNAKES
}

\author{
RON E. VANNIMWEGEN $\uparrow$ DIANE M. DEBINSKI \\ DEPARTMENT ECOLOGY, EVOLUTION AND ORGANISMAL BIOLOGY \\ IOWA STATE UNIVERSITY $\downarrow$ AMES
}

\section{$\uparrow \quad$ ABSTRACT}

Yellow Warblers (Dendroica petechia) are migratory songbirds found in high abundance in the tall willow (Salix boothii) habitats of Grand Teton National Park (GTNP). Willows are found in wet soils with high water tables and varying densities of exposed surface water. Dense surface area of water leads to thick, well foliated, continuous patches of $S$. boothii, which is the favored nesting habitat of Yellow Warblers. This water, however, also supports the favored prey base of the wandering garter snake (Thamnophis elegans vagrans), which has been known to prey on songbird nest contents when the opportunity arises. We hypothesized that nest territories containing high densities of surface water would also attract garter snakes, and increase the probability of nest failures. We found and monitored 28 Yellow Warbler nests, recorded their locations and fates (success or failure) and measured the density of surface water within each nest territory. We analyzed nest success with the logistic-exposure method coupled with comparisons of models with and without water density as an explanatory variable. Information theoretic model comparison consistently supported models with water density over those without. A significant correlation was found between water density within a nest territory and that nest's daily survival probability. The estimate of this effect was -0.049 (a logistic model parameter) with a standard error of 0.019 . Expressed alternatively, each 5-meter per territory increase in waterway density decreases the odds ratio of nest survival by
\end{abstract}

$21 \%$. While water density provides a trade off between nesting habitat and predation pressure, other predation causes and temporal water density variation likely contribute to overall warbler productivity in important ways as well.

\section{$\downarrow \quad$ INTRODUCTION}

Soil type, topography, and hydrology dictate the vegetation communities of montane meadows in the Greater Yellowstone Ecosystem, including those of Grand Teton National Park (GTNP) (Debinski et al. 1999). If we consider a hydrological continuum of meadows, we see a dominance of willows at the hydric end of that continuum (Kindscher et al. 1998). Both tall (Salix boothii) and short (Salix wolfii) willows are abundant in these meadows and provide dense nesting structure for a variety of songbirds. Eight years of bird surveys have shown Yellow Warblers (Dendroica petechia) to be the most dominant of songbird in GTNP willow habitats (unpublished data) consistent with earlier studies (Saveraid et al. 2001).

In these habitats, surface water can take the form of either flowing narrow waterways or shallow standing water of various areas. Higher densities of water are usually associated with thicker, taller willows, which are the preferred habitat of Yellow Warblers (Salt 1957, Knopf and Sedgwick 1992). Lower water densities are typified by thinner, sparsely foliated willows that can eventually 
transition to dry grassy or sagebrush dominated areas, and Yellow Warbler nests are rarely found in these areas.

Therefore, water density would seem to favor warbler productivity, but the same water that provides favorable nesting habitat also attracts wandering garter snakes (Thamnophis elegans vagrans), which prey primarily on small aquatic fauna such as amphibians, slugs, invertebrates, and the occasional small fish (Koch and Peterson 1995). Garter snakes are also adept at climbing through the dense but thin branch network of the willow growth form. As a result, while foraging for their highly available aquatic food, snakes could be opportunistically attracted to the behavior of adult warblers overhead, leading to an easily acquired and nutritious meal of nest contents.

Many recent studies of nest success have investigated the effect of broad scale landscape features on nest survival (Winter 1999, Herkert et al. 2003, Phillips et al. 2003), especially studies conducted in fragmented habitats interspersed with agricultural communities (e.g., Fletcher and Koford 2003). Our study focused on relatively pristine habitats and sought to measure local features, mainly water density, at the spatial level of the nest territory. We hypothesized that areas of high water density would support high nest density, and furthermore that individual nest territories with higher water densities would suffer higher predation rates.

Using a logistic-exposure method of analyzing nest success (Shaffer 2004), we predicted that water density within the nest territory would be negatively correlated with daily nest survival probabilities. We supported this correlation by comparing models with and without water density as an explanatory factor, using information-theoretic techniques (Anderson and Burnham 2000, Anderson and Burnham 2002) based on Akaike Information Criteria (AIC).

\section{METHODS}

We chose two large willow sites to conduct our study: the Pacific Creek site (PC site) and the Willow Flats site (WF site). Both contained large continuous patches of tall willows with a high abundance of warbler nests and an adequate variation in water density in the nest territories. Whether the water was a moving waterway or a standing volume of stationary water, we defined "waterway density" as the length of water-land interface in each 20-meter radius circle with a nest at its center. This density is expressed as meters per territory. Territories were assumed to be roughly equal in size after plotting nest locations in a geographic information system (GIS) and finding a mean distance between nests of 40 meters with very low variance. In other words, the warblers "pack" their nests in preferred habitat with a predictable uniform pattern.

We chose waterway density rather than the nearest distance to a waterway due to the circuitous nature of waterways in our study areas. Distance measures are adequate with linear edges, but could be misrepresentative of the water effect in situations such as that depicted in Figure 1. Here, equal distance measures could relate to quite different predator densities. We measured waterway density using ESRI® ArcMap 8.3 (ESRI 2002).

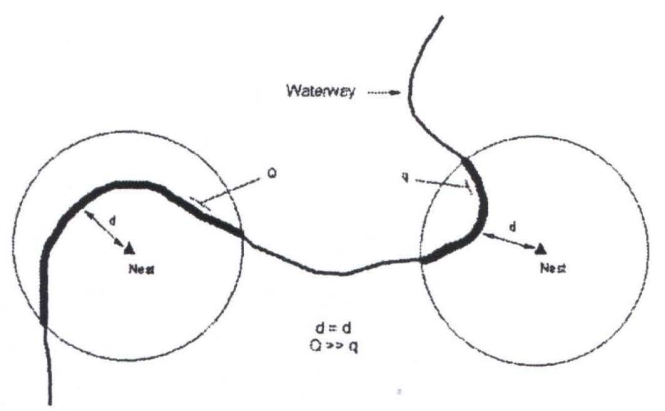

Figure 1. Potential discrepancy between distance and density measures of linear landscape features when they are nonlinear in shape. The distance measures (d) are equal for the two nests (black triangles within circular territories) while the quantity measures are quite unequal (length of the $\mathrm{Q}$ segment is more than twice that of the q segment).

We found 14 nests in each site and monitored them every two to four days until their fate was determined. We chose the least invasive observation methods possible, using mirror poles to inspect nest contents from a distance, while trying not to leave a dead end human trail that stopped at any given nest (Martin and Geupel 1993, Rodewald 2004). In addition, if a female was seen on the nest, we assumed the nest was still active and did not inspect the contents unless she flushed. Ultimate successes were assigned to nests that were found empty near the expected fledge date and fledglings were sited or heard begging in the immediate vicinity. Failures were assigned to nests found empty with no sign of parents or fledglings, even when near the expected fledge date. Fledge dates were predicted using photographs taken in 2002 of nestlings of known age. 
The logistic-exposure method of nest survival analysis treats each visitation interval as an observation, allowing for nest-specific features to be tested, whether continuous or categorical. It uses a generalized linear model (GLM) with a modified logit link function in PROC GENMOD in SAS 8.2 (SAS Institute 1999) to estimate a logistic parameter estimate, standard error, and $\chi^{2}$ significance test. We also measured more "traditional" effects, including nest height, vegetation height, nest position, distance to nearest waterway, distance to the nearest road (Klett and Johnson 1982), and site (PC site vs. WF site).

With an assortment of potential explanatory variables, we constructed a suite of candidate global models and chose the most supported model using AIC weights with information-theoretic methods. We then compared the chosen global model with all possible nested models to eventually determine the importance and estimate of our original variable of interest: waterway density.

\section{RESULTS}

In our first round of model comparisons, the most supported model contained waterway density, nest position, road distance, and site. Waterway density and site were both found to be significant $(\mathrm{P}$ $=0.02$ and $\mathrm{P}=0.01$, respectively) in this model, based on the $\chi^{2}$ GLM effect details. This global model fit the data well (Hosmer and Lemeshow goodness-of-fit: $\mathrm{P}=0.83$ ), and the most supported model was a nested subset of the waterway density, site, and waterway density-site interaction terms. Only the site and interaction terms were found to be significant $(\mathrm{P}<0.01$ and $\mathrm{P}=0.05$, respectively), suggesting that waterway density may be important in one site, but not the other. On this basis, we performed the logistic-exposure method to each site's data independently. In this case the PC site waterway density was significant $(\mathrm{P}=0.01)$, while the WF waterway density was not $(P=0.86)$.

Using the PC site parameter estimate of 0.048 we modeled daily and fledging probabilities based on a 26-day nesting cycle (Figure 2). Since this is a logistic model parameter, it is more intuitive to express it as an effect on the odds ratio of daily survival. Our parameter estimate translates to stating that a 5-meter increase in waterway density (meters per territory) results in a $28 \%$ drop in the daily survival odds ratio (Figure 3 ).

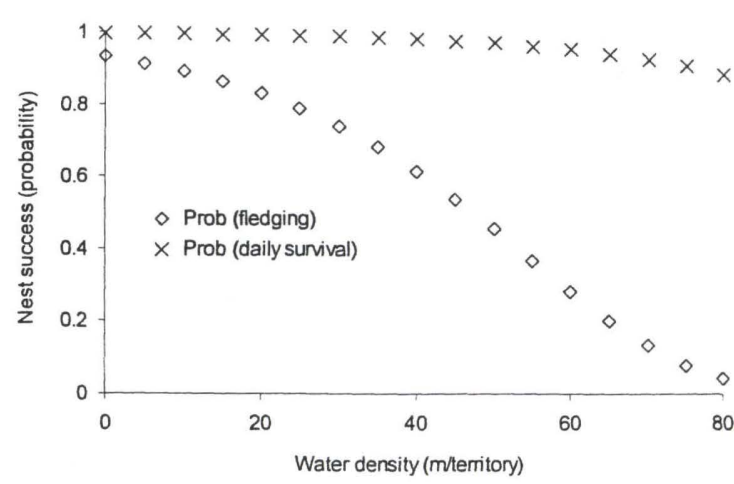

Figure 2. Projected probabilities of daily nest survival and fledging probability (surviving the entire nest period) for waterway lengths of 0 to 80 meters based on the parameter estimate of the waterway density variable from a logistic-exposure model (waterway density $=$ length of waterway within a 20 -meter radius territory of each nest). Fledging probability was based on daily survival raised to the power of 26 days (on average) in a Yellow Warbler nesting period. Parameter estimate and confidence interval was used from the Pacific Creek site.

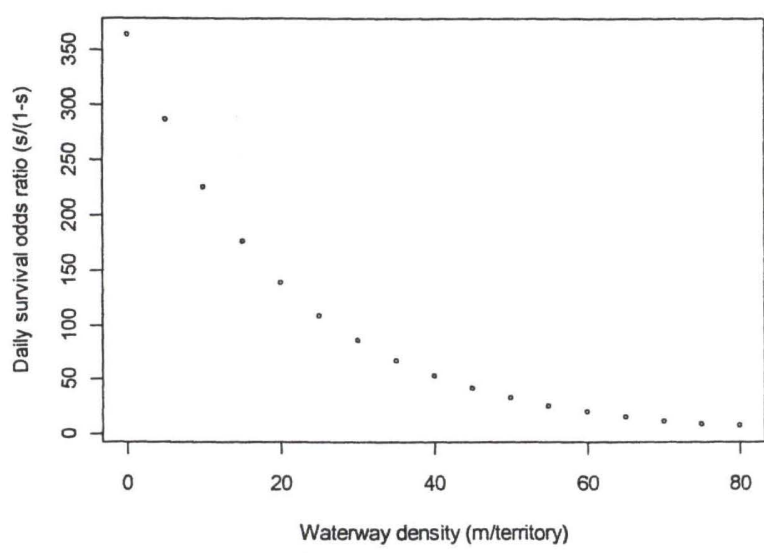

Figure 3. Projected probabilities of daily nest survival expressed as odds ratios vs. waterway densities of 0 to 80 meters based on the parameter estimate of the waterway density variable from a logistic-exposure model (waterway density $=$ length of waterway within a 20-meter radius territory of each nest). Parameter estimate was used from the Pacific Creek site.

\section{$\downarrow \quad$ DISCUSSION}

We hypothesized that waterway density would imply predator density and cause nest failures of Yellow Warblers in willow habitats. We predicted that waterway density would be negatively correlated with daily nest survival and we found evidence supporting this prediction in the PC site. This effect operates at the local scale of the nest territory, whereas waterway density on a broader scale implies more abundant nesting habitats (i.e., large, 
continuous aggregates of tall willows, Knopf and Sedgwick 1992). This implies a multi-scale tradeoff, but not necessarily of a static nature in which an optimal waterway density always favors nest success.

In our study sites, we personally witnessed several deep furrows lined with favorable nesting willows growing in dry to moist soils. These presumably contained open water in the recent past as evidenced by the vigor of the willow foliage. The willows could also be tapping into a high water table just under the surface of the soil. The lack of surface water in these areas did not provide the garter snakes primary prey base, and snake density may have been correspondingly low. Nearly all nests found in these areas were successful. Therefore, the spatio-temporal variation of a hydrological system could constantly change the optimal locations for nests. The alternately flooding and drying cycles, coupled with changing routes of water courses, could change the landscape scale distribution of nesting habitat, while simultaneously changing the local scale effect of waterway density. This environmental unpredictability does not allow either the Yellow Warblers or the garter snakes to gain an eventual advantage over the other (either through nestdetection on the snakes behalf or snake avoidance on the warbler's behalf).

This study needs two elements to strengthen the causal chain hypothesis of surface water attracting nest predators (snakes) via the predators primary prey base's attraction to surface water. First, snake surveys should be conducted within randomly located 20-meter radius "territories" within warbler nesting habitat of varying waterway density. This is a time consuming process when compared to the GIS waterway measures used in our study, but the data are needed to evaluate the reliability of our waterway proxy. Second, our study would greatly benefit from a larger sample size, both in numbers of nests and willow sites.

Two potential sites were ruled out because one was too dry with sparsely foliated willows, while the other was too wet, making the area virtually impenetrable. Both sites did not provide enough variation in waterway density (zero vs. nearly $100 \%$ ). Our WF site had an inordinately poor nest survival rate regardless of waterway density. A family of Common Ravens (Corvus corax) fledged and gradually spread throughout our nest sampling area in that site, possible confounding the results. With more sites and nests, a mixed model logisticexposure could model sites as random effects and our hypothesized explanatory variables as fixed effects
(Shaffer 2004). Additionally, the territory-packing nature of Yellow Warblers in favorable willow habitats introduces a spatial autocorrelation that must be taken into account. With several nests, random subsamples could be analyzed independently to obtain a measure of validation.

Finally, there are undoubtedly other significant predators affecting Yellow Warbler nest success. Avian predators such as the aforementioned ravens, Gray Catbirds (Dumetella carolinensis), American Robins (Turdus migratorius), and Redwinged Blackbirds (Agelaius phoeniceus) in neighboring marshes are of sufficient size to consume warbler nest contents. Three of the 28 nests suffered brood parasitism attempts by Brown-headed Cowbirds (Molothrus ater). Two were built with an additional layer to cover the parasitized clutch; of these two, one ultimately succeeded (in a dry territory) while the other failed (in a wet territory). The third parasitized nest fledged all nestlings, again in a dry territory.

Our hypothesis makes biological sense and we found evidence to support it in one study site. These should serve as preliminary results to warrant the expansion of the study and implement the improvements suggested. Songbird nest success studies in relatively pristine areas such as GTNP are rare and are worthy of more attention. This would allow us to characterize and compare natural determinants of nest success with the usual humaninduced fragmentation studies (Stephens et al. 2003).

\section{$\uparrow$ LITERATURE CITED}

Anderson, D.R., and K.P. Burnham. 2000. Model selection and multimodel inference : a practical information-theoretic approach. Springer, New York.

Anderson, D.R., and K.P. Burnham. 2002. Avoiding pitfalls when using information-theoretic methods. Journal of Wildlife Management 66:912-918.

Debinski, D. M., M .E. Jakubauskas, and $\mathrm{K}$. Kindscher. 1999. A remote sensing and GIS-based model of habitats and biodiversity in the Greater Yellowstone Ecosystem. International Journal of Remote Sensing 20:3281-3292.

ESRI. 2002. ArcMap 8.3. Environmental Systems Research Institute. Redlands, CA. 
Fletcher, R.J., and R.R. Koford. 2003. Spatial responses of Bobolinks (Dolichonyx oryzivorus) near different types of edges in northern Iowa. Auk 120:799-810.

Herkert J.R., D.L. Reinking, D.A. Wiedenfeld, M. Winter, J.L. Zimmerman, W.E. Jensen, E.J. Finck, R.R. Koford, D.H. Wolfe, S.K. Sherrod, M.A. Jenkins, J. Faaborg, S.K. Robinson. 2003. Effects of prairie fragmentation on the nest success of breeding birds in the midcontinental United States. Conservation Biology 17:587-594.

Kindscher, K, A. Frasier, M. E. Jakubauskas, and D. M. Debinski. 1998. Identifying wetland meadows in Grand Teton National Park using remote sensing and average wetland values. Wetlands Ecology and Management 5:265-273.

Klett, A.T., and D.H. Johnson. 1982. Variability in nest survival rates and implications to nesting studies. Auk 99:77-87.

Knopf, F.L., and J.A. Sedgwick. 1992. An experimental study of nest-site selection by Yellow Warblers. Condor 94:734-742.

Koch, E., and C.R. Peterson. 1995. Amphibians and Reptiles of Yellowstone and the Grand Teton National Parks. University of Utah Press, Utah.

Martin, T.E., and G.R. Geupel. 1993. Nestmonitoring plots - methods for locating nests and monitoring success. Journal of Field Ornithology 64:507-519.

Phillips, M.L., W.R. Clark, M.A. Sovada, D.J. Horn, R.R. Koford, and R.J. Greenwood. 2003. Predator selection of prairie landscape features and its relation to duck nest success. Journal of Wildlife Management 67:104114.
Rodewald, A.D. 2004. Nest-searching cues and studies of nest-site selection and nesting success. Journal of Field Ornithology 75:31-39.

Salt, G.W. 1957. An analysis of avifaunas in the Teton Mountains and Jackson Hole, Wyoming. Condor 59:373-393.

SAS Institute. 1999. SAS/STAT Users Guide. Version 8.2. SAS Institute, Cary, NC.

Saveraid, E.H., D.M. Debinski, K. Kindscher, and M.E. Jakubauskas. 2001. A comparison of satellite data and landscape variables in predicting bird species occurrences in the Greater Yellowstone Ecosystem, USA. Landscape Ecology 16:71-83.

Shaffer, T.L. 2004. A unified approach to analyzing nest success. Auk 121:526-540.

Stephens S.E., D.N. Koons, J.J. Rotella, and D.W. Willey. 2003. Effects of habitat fragmentation on avian nesting success: a review of the evidence at multiple spatial scales. Biological Conservation 115:101110.

Winter, M. 1999. Nesting biology of Dickcissels and Henslow's Sparrows in southwestern Missouri prairie fragments. Wilson Bulletin 111:515-526. 